\title{
Development of a Silica Surface Modified with Reactive Amino Group as an Immobilized Carrier for Use as Biosensor Material
}

\author{
Takaaki Isoda*, Risa Maeda, Ayako Minohoshi, \\ Makoto Kimura, Haruna Iwamoto and Mao Kuramoto \\ Department of Life and Environment Engineering, Faculty of Environmental Engineering, \\ University of Kitakyushu, 1-1 Hibikino, Wakamatsu, Kitakyushu 808-0135, Japan
}

(Received May 14, 2014; accepted January 6, 2015)

Key words: biosensor, material, silica, surface, amino group, fluorescent

In this study, the surface of a silica particle modified with a reactive amino group was developed as an immobilized carrier for use as a biosensor material. Silica particles with a diameter of $5 \mu \mathrm{m}$ were modified with $N$-2(aminoethyl)-3-amino-propyl trimethoxysilane as a silane coupling agent at $100{ }^{\circ} \mathrm{C}$ at heating rates of $2.2,3.0$, and $6.0^{\circ} \mathrm{C} / \mathrm{min}$. These particles were reacted with various concentrations of fluorescein isothiocyanate (FITC) at room temperature for $5 \mathrm{~min}$. FITC-labeled samples exhibited green fluorescence at $520 \mathrm{~nm}$, which was examined by a fluorescence microscope. The fluorescence intensity of a FITC-labeled silica surface was found to increase in two steps with increasing FITC concentration. The rate of increase in fluorescence intensity was higher in Step I than in Step II for all samples. However, the rate of increase in fluorescent intensity in Step I, as well as the amount of reactive amino groups on a silica surface, was strongly affected by the heating rate in the silane coupling reaction. On the basis of these results, conditions of silane coupling reaction and the effect of the conformation of modified amino groups on the silica surface on reactivity were discussed.

\section{Introduction}

Recently, biosensors, as well as quartz crystal microbalance and/or surface plasmon resonance sensors, have attracted attention as a novel biosensing technology that can obtain information about the interaction between a protein and another protein and/ or a protein and biopolymers such as nucleotides. The conjugation of proteins and

${ }^{\text {*} C o r r e s p o n d i n g ~ a u t h o r: ~ e-m a i l: ~ i s o d a @ k i t a k y u-u . a c . j p ~}$ 
biopolymers with a solid surface is a breakthrough technology for the development of biosensors. The surface chemistry of biomolecules has been studied extensively and can be categorized into the surface interaction between biomolecules and polar functional groups or the formation of a covalent bond between biomolecules and functional groups.

As examples of the former case, Patwardhan et al. ${ }^{(1)}$ found low sequence similarity among peptides strongly attracted to amorphous silica nanoparticles using combinatorial phage display methods. Cademartiria et $a l^{(2)}$ reported that morphologically different bacteriophages effectively physically adsorbed to silica particles prepared by silica surface modification with polyethylene glycol, carboxylic acid groups or amines. Chena et $a l^{(3)}$ developed amino-functionalized silica particles that can capture and release viruses. They used negatively charged silica beads functionalized with amino groups on spacer molecules of defined length to yield particles with a surface density optimized for efficient virus capture. Following capture, viruses can be released using soluble proteins or amino acid-based alkaline eluents.

We previously reported that the surfaces of silica particles modified with aminosilane could be rapidly immobilized with single-stranded nucleic acids in PBS solution at 37 ${ }^{\circ} \mathrm{C}$ to prevent their denaturation. ${ }^{(4)}$ The single-stranded nucleic acids trapped at the modified silica surfaces by hydrogen bonding were further conjugated by derivatives of a fluorescent label to form complexes. We observed changes in the fluorescence intensities of these complexes originating from interactions between single-stranded nucleic acid bases and aromatic compounds.

Examples of the other category, which focuses on covalent bonding between biomolecules and functional groups, are also abundant. Kimura et al. ${ }^{(5)}$ prepared polystyrene (PS) microparticles modified with schizophyllan (SPG) or polysaccharide. A terminal site of SPG was modified with an amino group and bound covalently to a carboxyl group on the support surface to form the composite PS•SPG. Petkovaa's group $^{(6)}$ used silica particles as solid supports for alcohol dehydrogenases (HLADHs). The immobilization of HLADHs was achieved by the formation of a covalent bond with glutaraldehyde, and HLADHs retained their alcohol dehydrogenation activity. Zhang et al. ${ }^{(7)}$ modified porous silica particles with different surface active groups for the covalent immobilization of porcine pancreas lipase (PPL). They reported that organosilanes combined with reactive end amino or epoxy groups through silanization. Polyethylenimine and a long-chain alkyl silane coupling agent were also used in the modification process. Good coupling yields in the range of $86.2-158.2 \mathrm{mg}$ for native PPL per gram of carrier were achieved.

As exemplified above, the conjugation of biopolymers with a functional group on a surface is an important method for the development of biosensor materials. However, the lot-to-lot reproducibility of such an immobilization support remains poorly understood. The effect of the structure with functional groups on a solid surface has seldom been investigated. It is possible for the effect to affect the reactivity of the functional groups with substances such as biopolymers.

In this study, the surface of a silica particle modified with a reactive amino group is developed as an immobilized carrier for use as a biosensor material. We fabricate silica particles with surfaces modified by aminoalkyl chains at different heating rates of the 
silane coupling reaction. The amino groups introduced on the surfaces can react with fluorescein isothiocyanate (FITC) through thiourea bonding, resulting in a conjugate between a fluorescence label and an inorganic material. The green fluorescence intensity of the conjugate, which reflects the amount of reactive amino groups bound to FITC, is investigated. On the basis of these results, conditions of the silane coupling reaction and the conformation of amino groups on the solid surface are assessed.

\section{Materials and Methods}

\subsection{Preparation of silica surfaces modified with aminoalkyl chains}

Silica surfaces modified with aminoalkyl chains were prepared as previously reported.(4) Hypersil silica (GL Science Co., Ltd., Tokyo, Japan; particle diameter: $5 \mu \mathrm{m}$ ) was used as a solid carrier. $\mathrm{N}$-2-Aminoethyl-3-aminopropyltrimethoxysilane (Shin-Etsu Chemical Co., Ltd., Tokyo, Japan; KBM-603: abbreviated to $\mathrm{NH}_{2}$-silane) was used as a silane coupling agent. The structure of $\mathrm{NH}_{2}$-silane is shown in Fig. 1 (Step I). The reaction scheme is also outlined. Silanol was formed by the hydrolysis of $2 \% \mathrm{NH}_{2}$-silane in an aqueous solution at $20{ }^{\circ} \mathrm{C}$ for $30 \mathrm{~min}$. The silane coupling reaction of silanol with silica particles was carried out at $100{ }^{\circ} \mathrm{C}$ for $10 \mathrm{~min}$ in a Teflon beaker on an electric hot plate. Three different heating rates of $2.2,3.0$, and $6.0{ }^{\circ} \mathrm{C} / \mathrm{min}$ were examined several times under controlled conditions. Three different samples of silica particles modified with aminoalkyl chains (abbreviated as $\left[\mathrm{NH}_{2}\right.$-silane $] / \mathrm{SiO}_{2}$ ) were obtained; these samples are labeled samples A (heating rate of $6.0^{\circ} \mathrm{C} / \mathrm{min}$ ), B (heating rate of $3.0^{\circ} \mathrm{C} / \mathrm{min}$ ), and $\mathrm{C}$ (heating rate of $\left.2.2^{\circ} \mathrm{C} / \mathrm{min}\right)$.

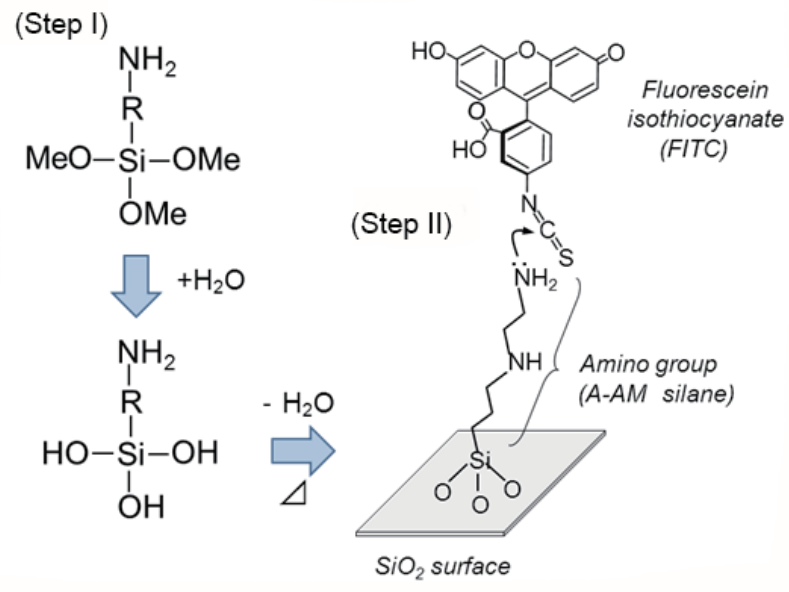

Fig. 1. (Color online) Reaction mechanism of aminosilane coupling on a silica surface. 


\subsection{Fluorescence labeling of reactive amino groups}

$\left[\mathrm{NH}_{2}\right.$-silane $] / \mathrm{SiO}_{2}$ was reacted with FITC, as shown in Fig. 1 (Step II). The reaction scheme is also outlined in Fig. 2(a). $\left[\mathrm{NH}_{2}\right.$-silane $] / \mathrm{SiO}_{2}(5 \mathrm{mg})$ was washed in THF under ultrasonic conditions for $2 \mathrm{~min}$, and then rinsed twice with distilled water (DW). FITC (1-100 $\mu \mathrm{g} / \mathrm{mL}$, Dojindo Laboratories Co., Ltd., Kumamoto, Japan) in PBS solution (20 $\mu \mathrm{L}$ ) was added as a fluorescent labeling solution, and then the mixture was incubated at $25{ }^{\circ} \mathrm{C}$ for $5 \mathrm{~min}$. The sample was washed twice with DW to give FITC-labeled silica particles ([FITC-NH${ }_{2}$-silane $\left.] / \mathrm{SiO}_{2}\right)$.

\subsection{Quantitative assay for labeled silica surfaces}

Fluorescence intensity was determined using a fluorescence microscope (U-RFLT50, Olympus, Tokyo, Japan) at a wavelength of $520 \mathrm{~nm}$, as discussed in Figs. 2(b) and 2(c). [FITC- $\mathrm{NH}_{2}$-silane] $/ \mathrm{SiO}_{2}(5 \mathrm{mg})$ was dispersed in $\mathrm{DW}(300 \mu \mathrm{L})$ and placed in one well of a culture slide (well size: $10 \mathrm{~mm}^{2}$, BD Co., Ltd., USA). After $5 \mathrm{~min}$, images were obtained at 15 arbitrary points in the cell and analyzed to determine the average intensity. Furthermore, the standard deviation was also obtained and showed an error range. The fluorescent intensity of FITC in PBS solution $(1-100 \mu \mathrm{g} / \mathrm{mL})$ was also measured to obtain a calibration curve.

(a) $[$ A-AM silane $] / \mathrm{SiO}_{2}$ particles (low purity) $5 \mathrm{mg}$

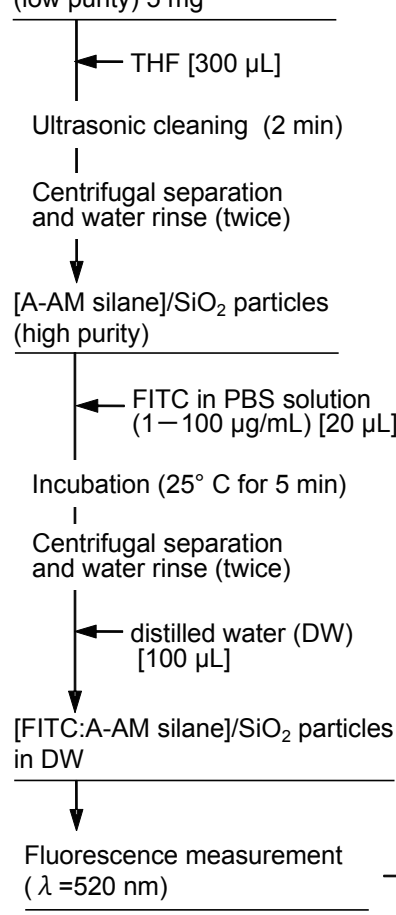

(b) FITC in PBS solution

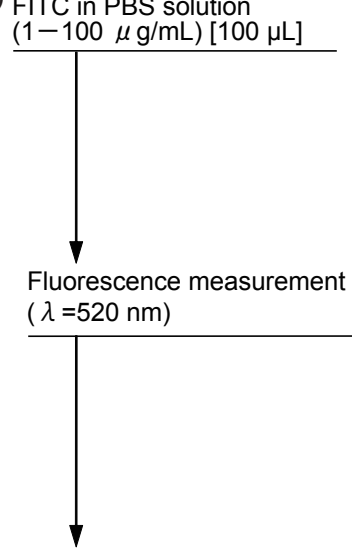

Calibration curve

(c)

Qualitative analysis of amino groups on [A-AM silane] $/ \mathrm{SiO}_{2}$ particles

Fig. 2. Flow chart outlining the preparation of $\left[\mathrm{FITC}-\mathrm{NH}_{2}\right.$-silane $] / \mathrm{SiO}_{2}$ for fluorescence analysis. 


\section{Results}

\subsection{Reactivity of aminoalkylated silica particles}

Figure 3 shows typical fluorescence micrographs of [FITC- $\mathrm{NH}_{2}$-silane] $/ \mathrm{SiO}_{2}$ particles. Particles dispersed in DW settled out uniformly at the bottom of a well. As a result, uniform green fluorescence was observed from that well. The intensity of green fluorescence increased with the concentration of FITC from 0 to $100 \mu \mathrm{g} / \mathrm{mL}$.

Figure 4 shows fluorescence micrographs of FITC solutions for comparison. A similar dependence of the fluorescence intensity on the concentration was confirmed; the intensity of green fluorescence increased with FITC concentration from 0 to $20 \mu \mathrm{g} / \mathrm{mL}$. The relative fluorescence intensities (RFIs) of FITC-labeled $\left[\mathrm{NH}_{2}\right.$-silane] $/ \mathrm{SiO}_{2}$ particles are summarized in Table 1. There are three different samples of silica particles, which are labeled samples $\mathrm{A}$ (heating rate of $6{ }^{\circ} \mathrm{C} / \mathrm{min}$ ), $\mathrm{B}$ (heating rate of $3{ }^{\circ} \mathrm{C} / \mathrm{min}$ ), and $\mathrm{C}$ (heating rate of $\left.2.2{ }^{\circ} \mathrm{C} / \mathrm{min}\right)$.
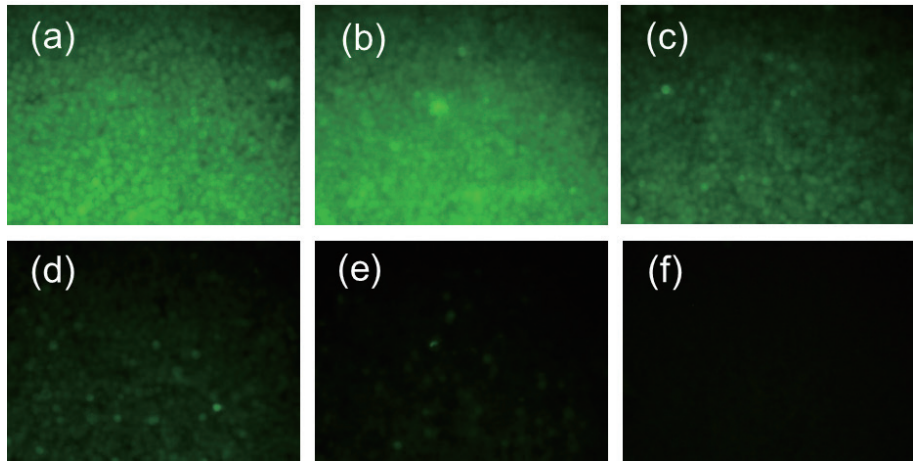

Fig. 3. (Color online) Fluorescence micrographs of FITC-labeled $\left[\mathrm{NH}_{2}\right.$-silane $] / \mathrm{SiO}_{2}$ particles (sample A). FITC concentrations: (a) 100, (b) 50, (c) 20, (d) 10, (e) 5, and (f) $0 \mu \mathrm{g} / \mathrm{mL}$.
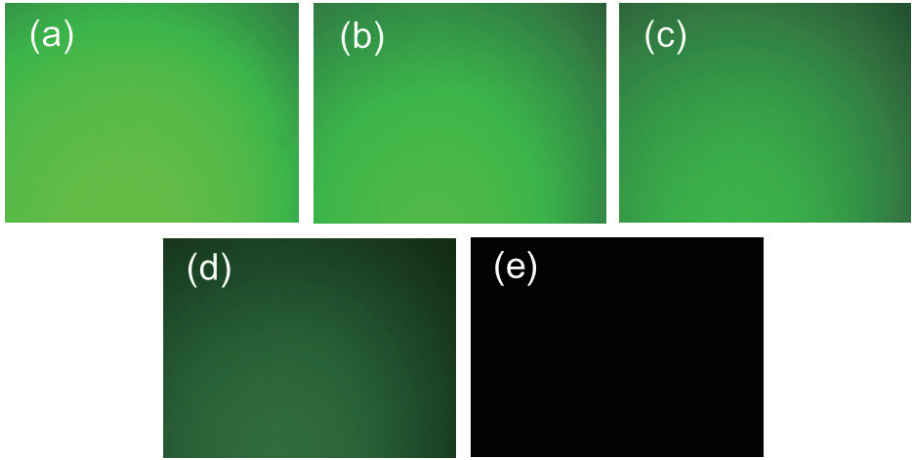

Fig. 4. (Color online) Fluorescence micrographs of FITC solution. FITC concentrations: (a) 20, (b) 15 , (c) 10 , (d) 5 , and (e) $0 \mu \mathrm{g} / \mathrm{mL}$. 
Table 1

Sensitivities of the fluorescence intensities of FITC-labeled $\left[\mathrm{NH}_{2}\right.$-silane $] / \mathrm{SiO}_{2}$ particles.

\begin{tabular}{|c|c|c|c|c|c|c|}
\hline \multirow{2}{*}{$\begin{array}{l}\text { FITC } \\
{[\mu \mathrm{g} / \mathrm{mL}]}\end{array}$} & \multicolumn{2}{|c|}{ Sample $A^{1)}$} & \multicolumn{2}{|c|}{ Sample B ${ }^{2)}$} & \multicolumn{2}{|c|}{ Sample $C^{3)}$} \\
\hline & Untreated & $\begin{array}{c}\text { Labeled } \\
\text { FITC }\end{array}$ & Untreated & $\begin{array}{c}\text { Labeled } \\
\text { FITC }\end{array}$ & Untreated & $\begin{array}{c}\text { Labeled } \\
\text { FITC }\end{array}$ \\
\hline 100 & $15 \pm 3$ & $228 \pm 3$ & $7 \pm 1$ & $142 \pm 7$ & $13 \pm 2$ & $124 \pm 2$ \\
\hline 50 & $11 \pm 1$ & $195 \pm 14$ & $9 \pm 1$ & $121 \pm 3$ & $12 \pm 2$ & $90 \pm 2$ \\
\hline 20 & $15 \pm 1$ & $158 \pm 4$ & $8 \pm 1$ & $62 \pm 3$ & $9 \pm 1$ & $78 \pm 2$ \\
\hline 10 & $11 \pm 1$ & $79 \pm 2$ & $8 \pm 1$ & $26 \pm 1$ & $10 \pm 1$ & $44 \pm 2$ \\
\hline 5 & $12 \pm 2$ & $41 \pm 2$ & $10 \pm 1$ & $7 \pm 3$ & $8 \pm 1$ & $10 \pm 3$ \\
\hline
\end{tabular}

Untreated $\left[\mathrm{NH}_{2}\right.$-silane $] / \mathrm{SiO}_{2}$ particles showed a RFI of less than 15 for all samples. Labeled samples showed that RFI depends on FITC concentration. The highest RFI was obtained for sample A, which was $228 \pm 3$ for a FITC concentration of $100 \mu \mathrm{g} / \mathrm{mL}$. The maximum RFIs of samples B and C were lower than that of sample A and were $142 \pm 7$ and $124 \pm 2$, respectively, for a FITC concentration of $100 \mu \mathrm{g} / \mathrm{mL}$. Fluorescence intensity depended on sample type in the order of sample A $>>B>C$ when the concentration of FITC was high. However, the order of fluorescence intensity changed to sample A $>C$ $>\mathrm{B}$ when the concentration of FITC decreased to $20 \mu \mathrm{g} / \mathrm{mL}$. At a FITC concentration of $20 \mu \mathrm{g} / \mathrm{mL}$, RFIs were $158 \pm 4$ for sample A, $78 \pm 2$ for sample C, and $62 \pm 3$ for sample B. When the concentration of FITC was reduced $(5 \mu \mathrm{g} / \mathrm{mL})$, sample A had a RFI of 41 \pm 2 , while no fluorescence was observed in samples $C$ and $B$ with RFIs of $10 \pm 3$ and $7 \pm$ 3 , respectively. The reactivity of silica surfaces modified with aminoalkyl silane clearly differed among various samples treated at different heating rates in the silane coupling reaction.

\subsection{Sensitivities of fluorescence intensity}

Figure 5 shows the relationship between the concentration of FITC labeling solution and the RFI of FITC-labeled $\left[\mathrm{NH}_{2}\right.$-silane $] / \mathrm{SiO}_{2}$ particles. Figure 5(a) shows the sensitivity of fluorescence for sample A, which was treated at a heating rate of $6.0{ }^{\circ} \mathrm{C} /$ min. RFI increased markedly from $41 \pm 2$ for a FITC concentration of $5 \mu \mathrm{g} / \mathrm{mL}$ to $158 \pm$ 4 for a FITC concentration of $20 \mu \mathrm{g} / \mathrm{mL}$. Above a FITC concentration of $20 \mu \mathrm{g} / \mathrm{mL}, \mathrm{RFI}$ increased moderately up to $228 \pm 3$ for a FITC concentration of $100 \mu \mathrm{g} / \mathrm{mL}$.

These results suggest that the reaction of FITC with an amino group on the surface of silica involves two steps. Hereafter, the concentration of FITC at which the reaction changes from Step I to Step II (point S in Fig. 5) is defined as $C_{\mathrm{f}}$. The rates of increases in the fluorescence intensities of Steps I and II are defined as $I_{1}$ and $I_{2}$, respectively.

Figure $5(\mathrm{~b})$ shows the sensitivity of fluorescent labeling for sample B, which was treated at a heating rate of $3.3{ }^{\circ} \mathrm{C} / \mathrm{min}$. RFI increased moderately from $7 \pm 3$ for a FITC concentration of $5 \mu \mathrm{g} / \mathrm{mL}$ to $121 \pm 3$ at $C_{\mathrm{f}}$ of $50 \mu \mathrm{g} / \mathrm{mL}$. Above $C_{\mathrm{f}}$, RFI increased slightly up to $142 \pm 7$ for a FITC concentration of $100 \mu \mathrm{g} / \mathrm{mL}$. It is clear that the $I_{1}$ and $I_{2}$ of sample B are lower than those of sample A, while the $C_{\mathrm{f}}$ of sample B is higher than that of sample A. 


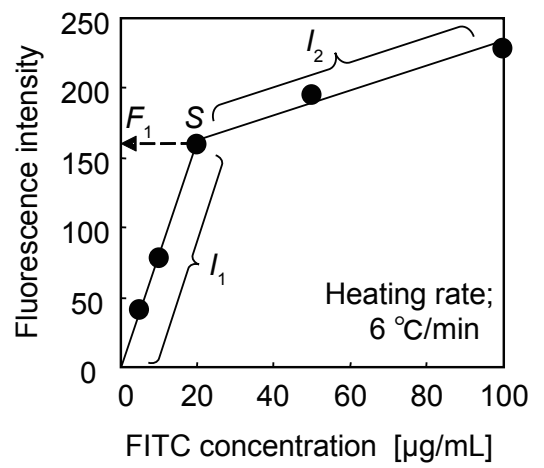

(a)

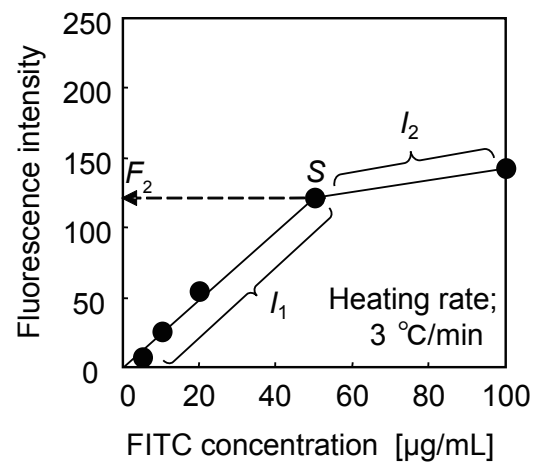

(b)

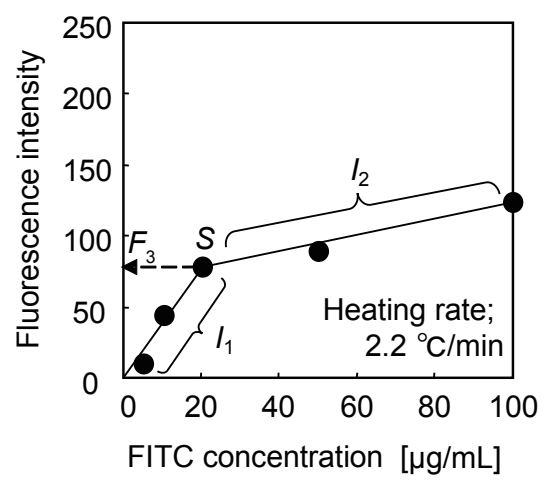

(c)

Fig. 5. RFI of FITC-labeled $\left[\mathrm{NH}_{2}\right.$-silane $] / \mathrm{SiO}_{2}$ particles as a function of the FITC concentration.

Figure 5(c) shows the sensitivity of fluorescent labeling for sample $\mathrm{C}$, which was treated at a heating rate of $2.0{ }^{\circ} \mathrm{C} / \mathrm{min}$. The fluorescence intensity of Step I increased negligibly and was determined to be $10 \pm 3$ for a FITC concentration of $5 \mu \mathrm{g} / \mathrm{mL}$ and 78 \pm 2 at $C_{\mathrm{f}}$ of $20 \mu \mathrm{g} / \mathrm{mL}$. However, the RFI continued to increase above $C_{\mathrm{f}}$ and was $124 \pm$ 2 for a FITC concentration of $100 \mu \mathrm{g} / \mathrm{mL}$.

These results show that $I_{1}$ was larger than $I_{2}$ in all samples. Furthermore, $I_{2}$ continued to increase above $C_{\mathrm{f}}$. However, all samples exhibited different $C_{\mathrm{f}}$ and/or $I_{1}$ values obtained by varying the heating rate in the silane coupling reaction step. 


\subsection{Determination of the amount of modified amino groups on silica surface}

Figure 6 shows a schematic model of changes in fluorescence intensity. FITC is a typical reactive reagent in the field of biochemistry, which is possible to bind an amino group of protein, cells, or tissues under reaction conditions at room temperature for a few minutes. ${ }^{(4)}$ We assumed that the reaction efficiency between the amino group and FITC is sufficiently high under the experimental conditions. A FITC molecule reacts with one amino group on a silica surface and forms a thiourea bond as shown in Fig. 1 (Step II). Hereafter, $\alpha$ is the number of FITC molecules and $\beta$ is the number of amino groups on a silica surface. Figure 6(a) shows a case of $\alpha<\beta$. A FITC molecule can be reacted with one amino group; therefore, fluorescence intensity is assumed to increase with increasing number of amino groups. Figure 6(b) shows a case of $\alpha=\beta$, which indicates the amount of reaction for FITC equal to the number of amino groups on a silica surface. Figure 6(c) shows a case of $\alpha>\beta$.

Theoretically, fluorescence intensity achieves a constant value because there is no amino group that can possibly react with FITC anymore.

Figure 7 shows the calibration curve obtained for FITC concentration against fluorescence intensity. There is good correlation between FITC concentration and fluorescence intensity. Fitting the data with a linear approximation gave a correlation coefficient of 0.9425 .

On the basis of the principle shown in Fig. 6, the amount of modified amino groups on a silica surface was determined by analyzing the information presented in Figs. 5 and 7. The analysis was carried out as follows: A linear approximation equation was obtained for reaction Step I in Fig. $5\left(I_{1}\right)$,

$$
y=a x+b
$$

Here, $a$ and $b$ are the slope and $y$-intercept, respectively. A linear approximation equation was also obtained for reaction Step II in Fig. $5\left(\mathrm{I}_{2}\right)$,

$$
y=m x+n .
$$

Here, $m$ and $n$ are the slope and $y$-intercept, respectively. The $y$-coordinate of the S point in Fig. 5 was calculated using eqs. (1) and (2):

$$
y=(b m+n a) /(m-a)=F_{i} .
$$

In eq. (3), $F_{i}(i=1-3)$ is the RFI at the $\mathrm{S}$ point. Using these equations, the $F_{i}$ values of samples A-C were obtained. Each $F_{i}$ was substituted into the calibration curve in Fig. 7 to give real $C_{\mathrm{f}}$ concentrations $\left(C_{1}-C_{3}\right)$. These obtained values are summarized in Table 2 .

Each FITC molecule reacted with a reactive amino group on a silica surface to form a thiourea bond. Therefore, the total amount of reactive amino groups on a silica surface equals the amount of FITC calculated from the real $C_{\mathrm{f}}$ concentration, which was defined as 
Example of fluorescence intensity changes
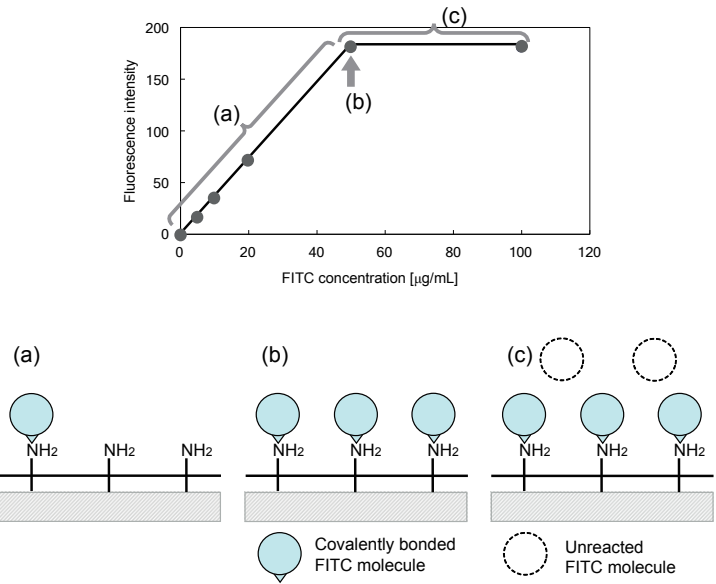

Fig. 6. (Color online) Schematic model of changes in fluorescence intensity.

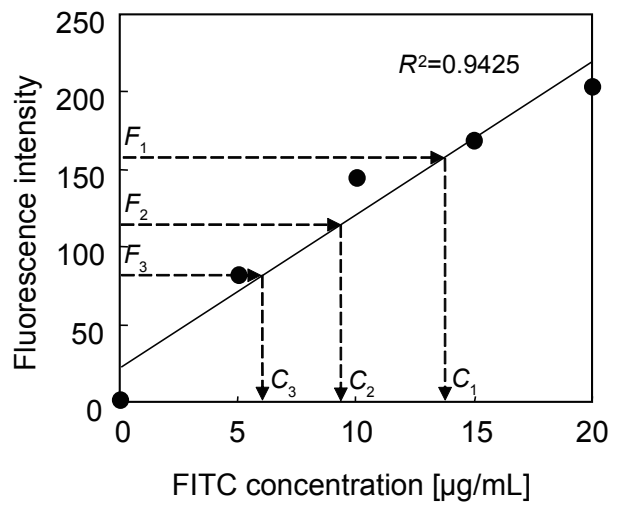

Fig. 7. Relative fluorescence of FITC as a function of the FITC concentration (calibration curve).

Table 2

Amount of amino groups on $\left[\mathrm{NH}_{2}\right.$-silane $] / \mathrm{SiO}_{2}$ particles.

\begin{tabular}{lccc}
\hline Sample & $\begin{array}{c}\text { Fluorescence intensity; } \\
F_{i}\end{array}$ & $\begin{array}{c}\text { Real FITC } \\
\text { concentration; } \\
C_{\mathrm{f}}[\mu \mathrm{g} / \mathrm{mL}]\end{array}$ & $\begin{array}{c}\text { Amount of amino } \\
\text { groups; } A_{\mathrm{a}}[\mathrm{mmol} / \mathrm{g}]\end{array}$ \\
\hline $\mathrm{A}$ & $F_{1}=177$ & $C_{1}=15.8$ & $8.12 \times 10^{-3}$ \\
$\mathrm{~B}$ & $F_{2}=117$ & $C_{2}=9.68$ & $4.98 \times 10^{-3}$ \\
$\mathrm{C}$ & $F_{3}=68$ & $C_{3}=4.68$ & $2.40 \times 10^{-3}$ \\
\hline & & Heating rates: 1$) 6,2) 3$, and 3$) 2.2^{\circ} \mathrm{C} / \mathrm{min}$
\end{tabular}




$$
A_{\mathrm{a}}=C_{\mathrm{FITC}} / S_{\mathrm{p}} \text {. }
$$

Here, $A_{\mathrm{a}}$ is the total amount of reactive amino groups $(\mathrm{mmol} / \mathrm{g}), C_{\mathrm{FITC}}(\mathrm{mmol})$ is the amount of FITC calculated from the real $C_{\mathrm{f}}$ concentration $(\mu \mathrm{g} / \mathrm{mL})$ and $S_{\mathrm{p}}$ is the weight of silica particles $(\mathrm{g})$. $A_{\mathrm{a}}$ values determined for samples $\mathrm{A}-\mathrm{C}$ are also summarized in Table 2.

$A_{\mathrm{a}}$ is the maximum amount of reacted amino groups with FITC that corresponds to the saturated state in Fig. 6(b). $A_{\mathrm{a}}$ values increased with the heating rate in the silane coupling reaction step, showing $8.12 \times 10^{-3} \mathrm{mmol} / \mathrm{g}$ reactive amino groups for sample A, $4.98 \times 10^{-3} \mathrm{mmol} / \mathrm{g}$ for sample $\mathrm{B}$, and $2.40 \times 10^{-3} \mathrm{mmol} / \mathrm{g}$ for sample $\mathrm{C}$.

\section{Discussion}

In this study, we predicted a change of reactive aminoalkyl groups formed on the silica surface using a reactive probe compound. In particular, fluorescent probe molecules are widely used for the determination of a surface chemical structure. ${ }^{(4)}$ In this study, we also used FITC as a probe compound and discussed the relationship between the reactivity and surface structure of each sample.

Figure 8 shows a schematic illustration of a silica surface modified with amino groups. In the first reaction, the silane compound was easily changed to silanol by hydrolysis with water at room temperature for $30 \mathrm{~min}$, as shown in Step I in Fig. 8.(4) In the second reaction, the hydroxyl groups of silanol were covalently bonded to the hydroxyl groups on the silica surface by condensation to form a silica surface modified with aminoalkyl chains. ${ }^{(4)}$ The intermediate reaction is shown in Step II (1) in Fig. 8. In this study, we also examined three types of silica surface modified with an aminoalkyl group, which was changed by the heating rate of the silane coupling reaction. The predicted reaction mechanism is outlined in Step II (2) in Fig. 8. There is potential for a side reaction where the silanol compound further reacted with the silanemodified surface, which possesses unreacted hydroxyl groups. Therefore, two types of conformation may be formed, namley, long-chain structure [Fig. 8(a) $]^{(3)}$ and short-chain structure [Fig. 8(b)] of aminoalkyl chains, as reported previously. ${ }^{(3,8)}$ FITC substituted with an isothiocyanate group will access the long-chain structure of an aminoalkyl chain easily because the spatial degree of freedom of this structure is higher than that of the short-chain structure.

Our results also suggest that the reactivity of the silica surface is affected by the heating rate of the silane coupling reaction because the formation of the aminoalkyl groups was affected. The amount of amino groups on surface $A_{\mathrm{a}}$ increased in the order sample $\mathrm{C}<\mathrm{B}<\mathrm{A}$ (Table 2). Therefore, it is possibile that the formation of reactive aminoalkyl groups, such as a long-chain structure on a silica surface, increases with increasing heating rate of the silane coupling reaction. In this study, we found that the heating rate of the silane coupling reaction is an important factor for the preparation of a silica surface modified by a more reactive amino group. 
(Step I)

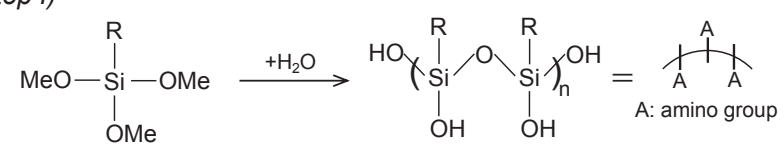

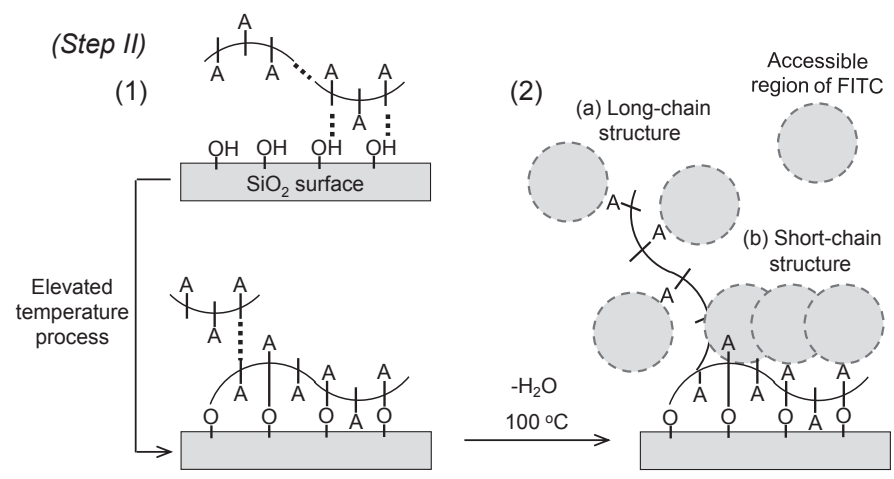

Fig. 8. Schematic illustration of a silica surface structure modified with an amino group.

\section{Conclusions}

We found that the reactivity of a silica surface is affected by the heating rate of a silane coupling reaction. Our results show that the fluorescence intensity of FITCsilica increased in two steps with the concentration of FITC. The rate of increase in fluorescence intensity was higher for Step I than for Step II in all samples. The isothiocyanate group in FITC selectively reacted with primary amine groups, such as that in an aminoalkyl group, to form a thiourea bond between both functional groups. Therefore, the reactivity of modified amino groups on the surfaces of silica particles must reflect the conformation of aminoalkyl groups. FITC molecules can easily access an amino group when the silane coupling reaction progresses as chain growth at a high heating rate of $6{ }^{\circ} \mathrm{C} / \mathrm{min}$. As a result, a high reactivity is observed and the fluorescence intensity increases markedly. In contrast, FITC molecules cannot easily access an amino group when the silane coupling reaction produces a short-chain structure at a low heating rate of $2.2{ }^{\circ} \mathrm{C} / \mathrm{min}$. A low reactivity and a moderate increase in fluorescence intensity are observed in this case.

\section{Acknowledgements}

This work was supported by the Japan Society for the Promotion of Science through a Grant-in-Aid for Scientific Research [Scientific Research (C): 23560409]. We also acknowledge Shin-Etsu Chemical Co., Ltd., Japan for providing the silane compound KBM-603. 


\section{References}

1 S. V. Patwardhan, S. F. Emami, R. J. Berry, S. E. Jones, R. R. Naik, O. Deschaume, H. Heinz and C. C. Perry: J. Am. Chem. Soc. 134 (2012) 6244.

2 R. Cademartiria, H. Ananyb, I. Grossb, R. Bhayania, M. Griffithsb and M. A. Brooka: Biomater. 31 (2010) 1904.

3 Z. Chena, F.-C. Hsub, D. Battigellib and H.-C. Changa: Anal. Chim. Acta 569 (2006) 76.

4 T. Isoda and R. Maeda: J. Funct. Biomater. 3 (2012) 601.

5 T. Kimura, K. Koumoto, M. Mizu, K. Sakurai and S. Shinkai: Chem. Lett. 12 (2002) 1240.

6 G. A. Petkovaa, K. Zárubaa and V. Král: Biochim. Biophys. Acta, Proteins Proteomics 1834 (2013) 1681.

7 Z. Zhang, F. He and R. Zhuo: J. Mol. Catal. B: Enzym. 94 (2013) 129.

8 B. Arkles: Chem. Tech. 29 (1999) 7. 